\section{Delaying Natural Flowering in Pineapple Through Foliar Application of Aviglycine, an Inhibitor of Ethylene Biosynthesis}

\author{
Ren-Huang Wang and Yu-Mei Hsu \\ Kaohsiung District Agricultural Research and Extension Station, Pingtung, \\ Taiwan, R.O.C.
}

\author{
Duane P. Bartholomew \\ Department of Tropical Plant and Soil Science, University of Hawaii, \\ Manoa, HI 96822
}

\begin{abstract}
Subbiyan Maruthasalam and Chin-Ho Lin ${ }^{1}$
Department of Life Sciences, National Chung Hsing University, 250 Kuo-Kuang Road, Taichung 402, Taiwan, R.O.C.
\end{abstract}

Additional index words. Ananas comosus var. comosus, bolting, forcing, precocious flowering

\begin{abstract}
In Taiwan, the major yield constraint in pineapple cultivation is natural flowering, which occurs when daylengths are shorter and nights are cooler. This natural (precocious) flowering increases the cost of cultivation and reduces the percentage of fruits of marketable size. Two field experiments were conducted to evaluate the inhibitory potential of aviglycine [(S)-trans-2-amino-4-(2 aminoethoxy)-3-butenoic acid hydrochloride, AVG] on natural flowering of 'Tainon 17' pineapple plants during the 2003 to 2004 and 2004 to 2005 cropping seasons. In the 2003 to 2004 season, bolting in the control exceeded $80 \%$ on 2 Mar. 2004, whereas no bolting was observed in the treatments. Inhibition of bolting by aviglycine (AVG) was dependent on the concentration and frequency of application. Bolting was less than $40 \%$ when plants were treated in Nov. and Dec. 2003 with $500 \mathrm{mg} \cdot \mathrm{L}^{-1}$ of AVG four times at 15-day intervals or with five applications made at 10-day intervals. For the 2004 to 2005 season, bolting of plants treated with 250 or $375 \mathrm{mg} \cdot \mathrm{L}^{-1}$ AVG was delayed 4 weeks relative to the control, whereas bolting was delayed 7 weeks by four or five applications of $500 \mathrm{mg} \cdot \mathrm{L}^{-1}$ of AVG applied at 10- or 15-day intervals. Both experiments showed that four to five applications of $500 \mathrm{mg} \cdot \mathrm{L}^{-1}$ of AVG at 10- or 15-day intervals delayed inflorescence emergence relative to the control for the duration of the treatments. We assume control was maintained for 1 to 2 weeks after treatments stopped. Based on these results, the date AVG treatments stop can be used to estimate the duration of delay in flowering. AVG inhibits ethylene biosynthesis and has the potential to be effectively used to delay or completely control the problem of precocious flowering and associated crop losses in pineapple.
\end{abstract}

Pineapple (Ananas comosus var. comosus) (Coppens d'Eeckenbrugge and Leal, 2003) is an important fruiting monocot and produces the only edible fruit in plants of the family Bromeliaceae. A major limitation that afflicts pineapple growers is the phenomenon of natural flowering, which results in unscheduled fruiting. The percentage of natural induction is highly unpredictable and the incidence may vary from $0 \%$ to $100 \%$ in any given year (Kuan et al., 2005), which causes serious scheduling problems for growers and, in particular, fresh market growers. Fruits produced by natural induction may not find a market, are costly to harvest because a relatively small percentage of these fruits mature at any given time in a field, and sometimes

Received for publication 18 Jan. 2007. Accepted for publication $28 \mathrm{Feb} .2007$.

${ }^{1}$ To whom reprint requests should be addressed; e-mail chinho@dragon.nchu.edu.tw pounds) of pineapple is a well-established commercial practice whereby pineapple can be induced to flower at any time of a particular year (almost irrespective of the temperature) and the fruits can be made available through nearly all of the year. Forcing efficiency will be high when forcing is done during the period when natural induction normally occurs. Forcing of pineapple is commonly done with ethylene, ethylene-releasing compounds such as ethephon, and $\mathrm{CaC}_{2}$, or acetylene when the plants are of sufficient size so as to yield fruits of marketable value (Bartholomew et al., 2003). Forcing also synchronizes flowering and produces a sharp ripening peak. In Taiwan (latitude $22^{\circ}$ to $26^{\circ} \mathrm{N}$ ), natural induction begins in late November as a result of sudden drops in temperature that coincide with passing cold fronts. Hence, most forcing is done during September and October and the fruits are harvested from March to May of the next year. If forcing of fully developed plants is delayed beyond October, they are highly prone to natural induction in the following months (Kuan et al., 2005).

Management of flowering of pineapple can be controlled to some extent by cultural practices that reduce plant stresses and promote vegetative growth (Bartholomew et al., 2003). Alternatively, growers can inhibit natural induction during susceptible periods by spraying a plant growth regulator and flowering can later be forced by spraying ethylene or ethephon. A number of plant growth regulators will inhibit flowering of pineapple under field conditions. Gowing and Leeper (1960) reported that low concentrations of certain phenoxyacetic acids forced pineapple, whereas higher concentrations inhibited it. Others (Martinez et al., 1997, 2000; Scott, 1993) found that foliar sprays of 2-(3-chlorophenoxy)-propionic acid (CPA) reduced the percentage of natural induction of pineapple. Cunha et al. (2003) tested the effect of many growth regulators on natural flowering of pineapple and found that CPA and paclobutrazole inhibited natural flowering of pineapple at concentrations of 90 and $240 \mathrm{mg} \cdot \mathrm{L}^{-1}$, respectively. Kuan et al. (2005) reported that aviglycine (AVG) prevented natural flowering in 'Tainon 18' pineapple under field conditions. AVG is an inhibitor of ethylene biosynthesis that is registered in the United States to improve fruit retention of apples and pears. Recently, Martinez et al. (2005) reported that Fruitone CPA $\left(20 \mathrm{mg} \cdot \mathrm{L}^{-1}\right.$ of a.i.) produced more than $90 \%$ inhibition of natural flowering in the pineapple hybrid $73-114$, which is also widely known as MD-2 (Chan et al., 2003), with four to six applications at weekly intervals starting from the last week of October or first week of November.

Although growth regulators can inhibit natural induction of pineapple, their practical application in pineapple fields has been limited by availability, cost, or both. The potential of AVG to control flowering in pineapple (Kuan et al., 2005) accompanied with the recent availability of large quantities of a commercial formulation of AVG has 
made it an attractive candidate for the control of a long-term problem in pineapple cultivation. Although Kuan et al. (2005) demonstrated that AVG will control pineapple flowering, the potential of AVG was not fully explored. The present study reports a more detailed investigation on the potential use of AVG for flowering control so that the grower can determine the date of initiation of reproductive development rather than depend on weather factors for this purpose.

\section{Material and Methods}

The current study was conducted in two cropping seasons (2003 to 2004 and 2004 to 2005) as two different experiments. The plant material used throughout this study was 'Tainon 17' ('Smooth Cayenne' $\times$ 'Rough') pineapple. The cultivar 'Tainon 17' was selected because of its popularity among the farmers of Taiwan (more than $70 \%$ of the pineapple area is occupied by 'Tainon 17') and its high tendency toward natural induction during winter months.

Expt. 1. The first experiment was carried out in a production field on the Lao-pei farm of the Taiwan Pineapple Corporation ( $22^{\circ} \mathrm{N}$ latitude). The experiment was initiated on 10 Nov. 2003 and the plants were treated with $5.0 \mathrm{ml}$ of a solution containing 500 $\mathrm{mg} \cdot \mathrm{L}^{-1}$ AVG (sold commercially as ReTain by Valent BioSciences Corp., Libertyville, IL), a water-soluble powder containing $15 \%$ a.i. supplemented with $0.02 \%$ BreakThru (Goldschmidt Chemical Corp., Hopewell, VA), a nonionic surfactant. The details regarding the number of treatments and frequency of AVG application are given in Table 1. Plants treated with $5 \mathrm{ml}$ of an aqueous solution containing $0.02 \%$ BreakThru alone were kept as a control. Inflorescences emerged in the leaf whorl, defined as bolting, were recorded weekly beginning on 2 Mar. 2004 until a plateau was reached and the values are expressed as a percentage.

Expt. 2. The second experiment was conducted during the 2004 to 2005 production season on a private farm near the Lao-pei farm. Seven-month-old 'Tainon 17' plants were treated with four to five applications each of $5 \mathrm{ml}$ of solutions containing 250 , 375 , or $500 \mathrm{mg} \cdot \mathrm{L}^{-1}$ of $\mathrm{AVG}$ and $0.02 \%$ Break-Thru at 10- or 15-d intervals between 10 Nov. and 25 Dec. 2004 (Table 2). Control plants were treated with $5 \mathrm{ml}$ of a solution containing $0.02 \%$ Break-Thru and the percentage of bolting was recorded as described earlier.

Statistical analyses. In both experiments, $\approx 30$ plants were used for each treatment and each treatment was replicated at least four times. The field blocks were arranged in a randomized complete block design. The collected percentage data were subjected to arcsine transformation and statistically analyzed using SAS analysis of variance (SAS Institute, Cary, NC) and the means were ranked using Fisher's least significant difference test.

\section{Results and Discussion}

The bolting percentage for plants treated with AVG was significantly less than that of the control group at all assessment dates for the 2003 to 2004 cropping season. Moreover, all the natural induction had occurred in the control plants by 2 Mar. 2004, the date of the first assessment, because bolting did not increase thereafter (Fig. 1). The greatest degree of control over natural induction occurred with a treatment interval of $10 \mathrm{~d}$, although at later assessment dates, the 10- and 15-d intervals were not significantly different. Bolting percentages for the $2 \times 15 \mathrm{D}$ and $3 \times 20 \mathrm{D}$ treatments were significantly higher than the other AVG treatments in the latter part of March. The significantly higher bolting percentage in the $2 \times 15 \mathrm{D}$ treatment relative to the $5 \times 10 \mathrm{D}$ and $4 \times 15 \mathrm{D}$ AVG treatments is assumed to be the result of flower induction that occurred attributable to early suspension of the treatments. Because both the $5 \times 10 \mathrm{D}$ and $3 \times 20 \mathrm{D}$ treatments ended on the same date, the higher bolting percentage in the latter treatment could be attributed to earlier recovery of 1-aminocyclopropane-1-carboxylic acid (ACC) synthase activity after the treatments ended. Continued treatment of plants with AVG at 10- or 15-d intervals likely would continue the inhibition of natural induction. Treatments were suspended
Table 1. Aviglycine treatment date, frequency and dosage for the 2003 to 2004 cropping season.

\begin{tabular}{lccccccc}
\hline & \multicolumn{7}{c}{ Date $(\mathrm{month} / \mathrm{d})$ and concn $\left(\mathrm{mg} \cdot \mathrm{L}^{-1}\right)$ of aviglycine } \\
\cline { 2 - 8 } Treatment $^{\mathrm{z}}$ & $11 / 10$ & $11 / 20$ & $11 / 25$ & $11 / 30$ & $12 / 10$ & $12 / 20$ & $12 / 25$ \\
\hline CK $^{\mathrm{y}}$ & 0 & 0 & 0 & 0 & 0 & 0 & 0 \\
$5 \times 10 \mathrm{D}(\mathrm{A})$ & 500 & 500 & - & 500 & 500 & 500 & - \\
$2 \times 15 \mathrm{D}(\mathrm{B})$ & 500 & - & 500 & - & - & - & 500 \\
$4 \times 15 \mathrm{D}$ (C) & 500 & - & 500 & - & 500 & - & - \\
$3 \times 20 \mathrm{D}(\mathrm{D})$ & 500 & - & - & 500 & - & 500 & - \\
\hline
\end{tabular}

${ }^{\mathrm{z}}$ No. of applications at the indicated interval (days).

${ }^{y}$ Five milliliters of a solution containing $0.02 \%$ Break-Thru alone.

Table 2. Aviglycine treatment date, frequency and dosage for the 2004 to 2005 cropping season.

\begin{tabular}{|c|c|c|c|c|c|c|c|}
\hline \multirow[b]{2}{*}{ Treatment $\mathrm{z}^{\mathrm{z}}$} & \multicolumn{7}{|c|}{ Date $(\mathrm{month} / \mathrm{d})$ and concn $\left(\mathrm{mg} \cdot \mathrm{L}^{-1}\right)$ of aviglycine } \\
\hline & $11 / 10$ & $11 / 20$ & $11 / 25$ & $11 / 30$ & $12 / 10$ & $12 / 20$ & $12 / 25$ \\
\hline$\overline{\mathrm{CK}^{\mathrm{y}}}$ & 0 & 0 & 0 & 0 & 0 & 0 & 0 \\
\hline $5 \times 10 \mathrm{D}(\mathrm{A})$ & 250 & 250 & - & 250 & 250 & 250 & - \\
\hline $4 \times 15 \mathrm{D}(\mathrm{B})$ & 250 & - & 250 & - & 250 & - & 250 \\
\hline $5 \times 10 \mathrm{D}(\mathrm{C})$ & 375 & 375 & - & 375 & 375 & 375 & - \\
\hline $4 \times 15 \mathrm{D}$ (D) & 375 & - & 375 & - & 375 & - & 375 \\
\hline $5 \times 10 \mathrm{D}(\mathrm{E})$ & 500 & 500 & - & 500 & 500 & 500 & - \\
\hline $4 \times 15 \mathrm{D}(\mathrm{F})$ & 500 & - & 500 & - & 500 & - & 500 \\
\hline
\end{tabular}

${ }^{\mathrm{z}}$ No. of applications at the indicated interval (days).

y Five milliliters of a solution containing $0.02 \%$ Break-Thru alone.

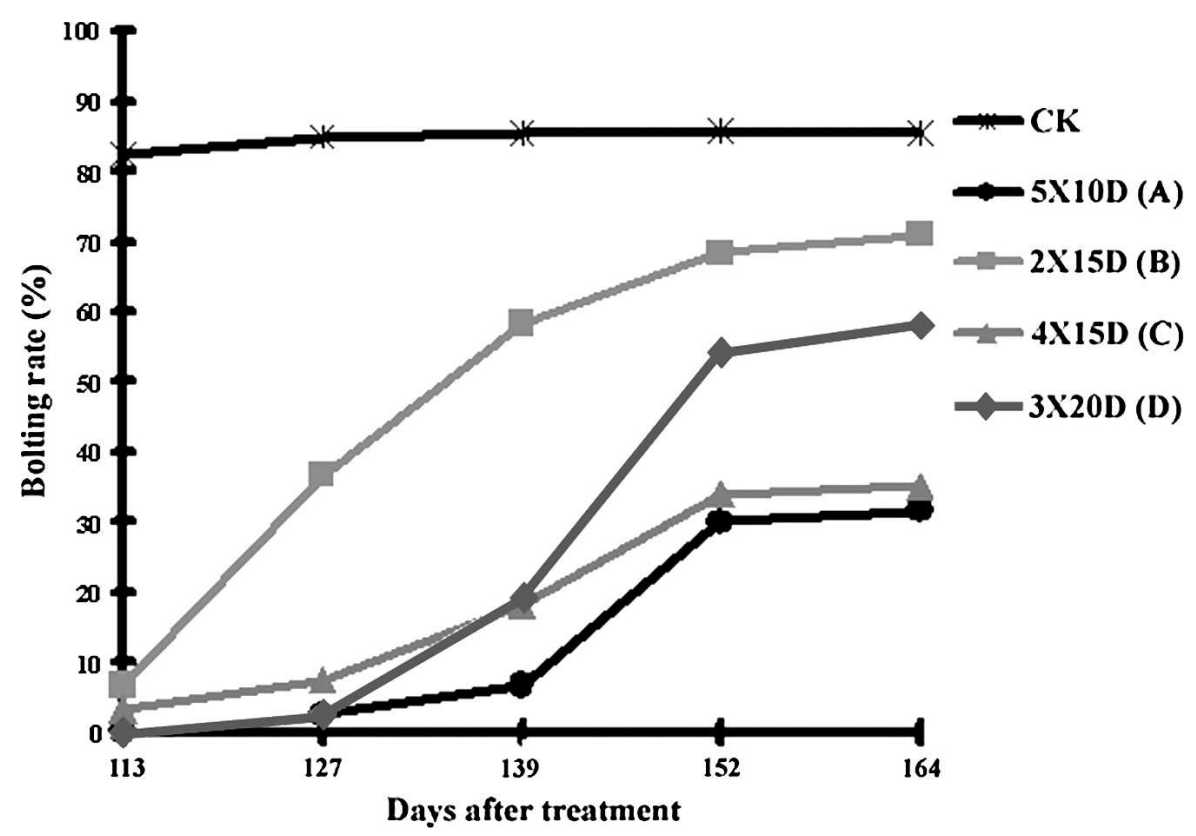

Fig. 1. Percentage of bolting of pineapple plants treated between 10 Nov. and 25 Dec. 2003 (2003 to 2004 cropping season) with $0(\mathrm{CK})$ or $500 \mathrm{mg} \cdot \mathrm{L}^{-1}$ aviglycine for the indicated number of times at $10-, 15-$, or 20-d intervals. 
at the end of December because previous results with 'Tainon 18' pineapple (Kuan et al., 2005) showed that stopping treatments at that time inhibited natural induction for at least another $60 \mathrm{~d}$, the potential of plants to bolt decreases as the average temperature increases in February and March, and treatment with AVG is costly.

Based on the results obtained from the 2003 to 2004 cropping season, a second trial was conducted in 2004 to 2005 to verify the frequency and interval of effective AVG treatments in delaying flowering. AVG concentration was reduced in hopes of finding a more cost-effective treatment that would control natural induction. A gradual increase in bolting percentage was observed in the control treatment until it reached $100 \%$ on 22 Mar. 2005, $133 \mathrm{~d}$ after the initial treatment (Fig. 2). At that time, all treatments had significantly lower bolting percentages than the control. Bolting percentage decreased significantly as the AVG dosage was increased, but there were few significant differences between 10- and 15-d application intervals at the same AVG concentration. Bolting percentage at the different concentrations of AVG increased over time, but it was less as the AVG concentration was increased. Bolting percentage for the $250 \mathrm{mg} \cdot \mathrm{L}^{-1} \mathrm{AVG}$ treatment was similar to the control at $169 \mathrm{~d}$ after treatment. The maximum bolting percentage for the 375 and $500 \mathrm{mg} \cdot \mathrm{L}^{-1} \mathrm{AVG}$ treatments remained significantly less than the control for the duration of the experiment, but differences were small for all but the $500-\mathrm{mg} \cdot \mathrm{L}^{-1}$ treatment applied at a 15 -d interval (Fig. 2). Either that treatment serves to indicate the variable nature of natural induction in pineapple or was the result of a lucky coincidence in timing of AVG applications just before the occurrence of natural induction. Differences in bolting percentage among treatments were small at the end of the study (Table 3), but a pineapple grower intent on managing flower induction would,

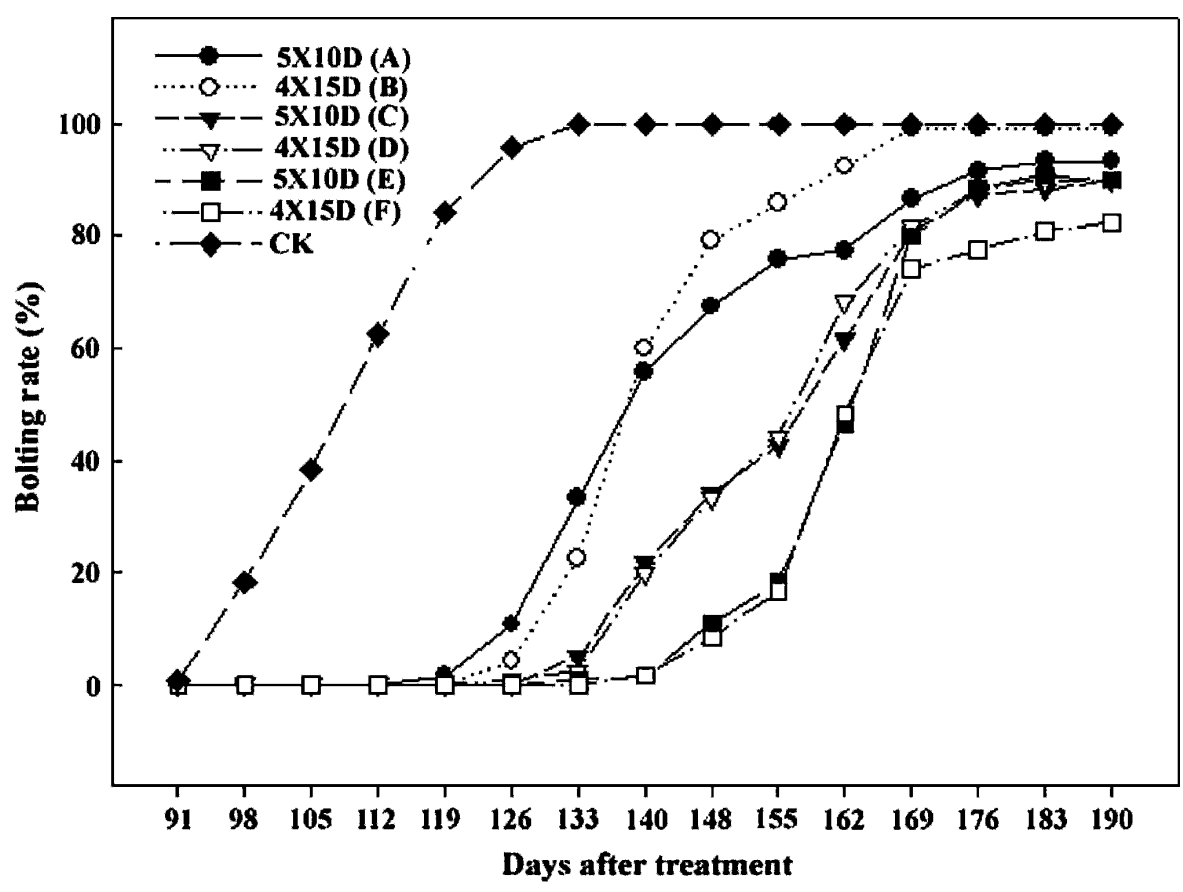

Fig. 2. Percentage of bolting of pineapple plants treated between 10 Nov. and 25 Dec. 2004 (2004 to 2005 cropping season) with $0(\mathrm{CK}), 250(\mathrm{~A}, \mathrm{~B}), 375(\mathrm{C}, \mathrm{D})$ or $500 \mathrm{mg} \cdot \mathrm{L}^{-1}(\mathrm{E}, \mathrm{F})$ of aviglycine for the indicated number of times at 10 - or $15-\mathrm{d}$ intervals.

Table 3. Effect of aviglycine (AVG) treatment on pineapple bolting during 2004 to 2005 cropping season.

\begin{tabular}{|c|c|c|c|c|c|}
\hline Treatment ${ }^{z}$ & $\begin{array}{c}\text { AVG concn } \\
\left(\mathrm{mg} \cdot \mathrm{L}^{-1}\right)\end{array}$ & $\begin{array}{l}\text { Date of } \\
\text { bolting } \\
\text { initiation }\end{array}$ & $\begin{array}{c}\text { Week of } \\
50 \% \text { bolting }\end{array}$ & $\begin{array}{l}\text { Date to reach } \\
\text { maximum } \\
\text { bolting rate }\end{array}$ & $\begin{array}{l}\text { Maximum } \\
\text { bolting } \\
\text { rate }(\%)\end{array}$ \\
\hline$\overline{\mathrm{CK}^{\mathrm{y}}}$ & 0 & 8 Feb. & $22 \mathrm{Feb}$. to $1 \mathrm{Mar}$. & 22 Mar. & $100.0 \mathrm{a}$ \\
\hline $5 \times 10 \mathrm{D}(\mathrm{A})$ & 250 & 8 Mar. & 22-29 Mar. & 24 May & $94.2 \mathrm{bc}$ \\
\hline $4 \times 15 \mathrm{D}(\mathrm{B})$ & 250 & 15 Mar. & 22-29 Mar. & 26 Apr. & $99.2 \mathrm{ab}$ \\
\hline $5 \times 10 \mathrm{D}(\mathrm{C})$ & 375 & 22 Mar. & 12-19 Apr. & 24 May & $92.5 \mathrm{c}$ \\
\hline $4 \times 15 \mathrm{D}(\mathrm{D})$ & 375 & 15 Mar. & 12-19 Apr. & 24 May & $92.5 \mathrm{c}$ \\
\hline $5 \times 10 \mathrm{D}(\mathrm{E})$ & 500 & 22 Mar. & 19-26 Apr. & 24 May & $91.7 \mathrm{c}$ \\
\hline $4 \times 15 \mathrm{D}(\mathrm{F})$ & 500 & 29 Mar. & 19-26 Apr. & 24 May & $85.8 \mathrm{c}$ \\
\hline
\end{tabular}

In a column, means followed by a common letter are not significantly different at the $5 \%$ level by Fisher's least significant difference test.

${ }^{z}$ No. of applications at the indicated interval (days).

${ }^{\mathrm{y}}$ Five milliliters of a solution containing $0.02 \%$ Break-Thru alone. depending on the farm schedule, either continue treatment beyond December or force flowering to achieve a planned result.

AVG-treated plants showed phytotoxic symptoms on young leaves with conspicuous yellowing. The degree of symptom increased with the frequency of AVG application and increase in AVG concentration. Most of the plants treated with $500 \mathrm{mg} \cdot \mathrm{L}^{-1} \mathrm{AVG}$ took $\approx 1$ month to recover, whereas some of the plants with severe symptoms of yellowing took more than 1 month to recover. No phytotoxicity was observed on pineapple plants treated with $0.02 \%$ Break-Thru alone. The role of phytotoxicity-induced ethylene production on flowering induction warrants further investigation.

The flowering induction of 'Tainon 17' in the 2003 to 2004 crop season occurred after 10 Dec. 2003. The data show that treating plants with $500 \mathrm{mg} \cdot \mathrm{L}^{-1}$ of AVG beginning on 10 Nov. with four applications at 15-d intervals would be sufficient to control flower induction resulting from low temperature from December to March of the following year. On 15 Dec. 2004, a cold front passed through the area where the experiments were conducted. AVG treatment on the day of the cold front did not effectively inhibit flowering in 'Tainon 17' pineapple (data not shown), possibly as a result of the accumulation effect conferred by endogenous ethylene biosynthesis.

In the 2004 to 2005 crop season, four consecutive treatments of $500 \mathrm{mg} \cdot \mathrm{L}^{-1}$ of AVG at 15-d intervals delayed inflorescence emergence by 7 weeks (Table 3; Fig. 2.), whereas the bolting was observed between 22 Feb. and 1 Mar. 2005 in the untreated plants. The delay in the onset of flowering of treated versus control plants could be accounted for by the 2 months of AVG treatments followed by a 1 - to 2 -week residual effect. Based on this fact, the final date to stop the AVG treatment can be used to determine the duration of delay in flowering.

The timing of inflorescence emergence (bolting) in pineapple depends primarily on the prevailing temperature (Malezieux et al., 1994) and occurs 60 to $75 \mathrm{~d}$ after floral induction begins. Any delay in flower induction resulting from $\mathrm{AVG}$ treatment delays bolting. AVG is a specific inhibitor of ACC synthase, which inhibits the plants' ability to synthesize ethylene and also its ability to initiate inflorescence development. However, the plants can recover their ability to synthesize ethylene some time after AVG treatment stops and, if conditions are favorable for induction, plants would also regain their ability to initiate inflorescence development.

\section{Conclusion}

In pineapple, the potential for natural induction under field condition declines as average air temperature increases. Thus, the need for control of natural induction in Taiwan is primarily between 1 Dec. and 28 
Feb., at which time plants will no longer be exposed to cold fronts and average temperature will have increased to the point at which vegetative growth rate increases, reducing plant sensitivity to natural induction. Based on the two field trial results, we conclude that four to five consecutive applications of $500 \mathrm{mg} \cdot \mathrm{L}^{-1}$ AVG made at 10 - or 15 -d intervals starting in the second week of November will delay natural flowering up to 7 weeks in 'Tainon 17' pineapples. The application schedule optimized in this study could also be extended for controlling precocious flowering in other cultivars of pineapple.

\section{Literature Cited}

Bartholomew, D.P., E. Malezieux, G.M. Sanewski, and E. Sinclair. 2003. Inflorescence, and fruit development and yield. p. 167-202. In: Bartholomew, D.P., R.E. Paull, and K.G. Rohrbach (eds.). The pineapple: Botany, production and uses. CABI Publishing, Wallingford, U.K.

Chan, Y.K., G. Coppens d'Eeckenbrugge, and G.M. Sanewski. 2003. Breeding and variety improvement, p. 33-55. In: Bartholomew, D.P., R.E. Paull, and K.G. Rohrbach (eds.).
The pineapple: Botany, production and uses. CABI Publishing, Wallingford, U.K.

Coppens d'Eeckenbrugge, G. and F. Leal. 2003. Morphology, anatomy and taxonomy. p. 13-32. In: Bartholomew, D.P., R.E. Paull, and K.G. Rohrbach (eds.). The pineapple: Botany, production and uses. CABI Publishing, Wallingford, UK.

Cunha, G.A.P.da, J.T.A. Costa, and D.H. Reinhardt. 2003. Natural flowering in pineapple: Inhibition by growth regulators. Fruits 58:2737.

Gowing, D.P. and R.W. Leeper. 1960. Studies on the relation of chemical structure to plant growth- regulator activity in the pineapple plant. I. Substituted phenyl and phenoxyalkylcarboxylic acids. Bot. Gaz. 121:143-151.

Kuan, C.S., C.W. Yu, M.L. Lin, H.T. Hsu, D.P. Bartholomew, and C.H. Lin. 2005. Foliar application of aviglycine reduces natural flowering in pineapple. HortScience 40:123126.

Lin, C.H., C.S. Kuan, Y.M. Hsu, and D.P. Bartholomew. 2005. Delaying Natural Flowering in Pineapple, p. 8. In: Anon. (ed.). Proceedings of the 5th ISHS International Pineapple Symposium, Port Alfred, South Africa.

Malezieux, E., J. Zhang, E. Sinclair, and D.P. Bartholomew. 1994. Predicting pineapple har- vest date in different environments, using a computer simulation model. Agron. J. 86:609617.

Martinez, A.R., D.U. Avila, and L.A. Gutierrez. 1997. Inhibicion de la floracion de la pina con diferentes dosis de Fruitone CPA en dos densidades de siembra (flowering inhibition in pineapple with different rates of $\mathrm{CPA}$ on two planting densities). Acta Hort. 425:347354.

Martinez, A.R., D.U. Avila, and L.R. Martinez. 2000. Rates of fruitone CPA in different applications number during day versus night to flowering inhibition in pineapple. Acta Hort. 529:185-190.

Martinez, A.R., L.R. Martinez, D.U. Avila, and A.D.A. Perez. 2005. Inhibition of the flowering pineapple MD-2 cv. using fruitone CPA at different rates and application dates, p. 9. In: Anon. (ed.). Proceedings of the 5th ISHS International Pineapple Symposium, Port Alfred, South Africa.

Scott, C.H. 1993. The effect of two plant growth regulators on the inhibition of precocious fruiting in pineapple. Acta Hort. 334:77-82.

Van Overbreek, J. and H.J. Cruzado. 1948. Note on flower formation in the pineapple induced by low night temperatures. Plant Physiol. 23:282285. 